Published in final edited form as:

Neuroscience. 2013 September 26; 249: 162-171. doi:10.1016/j.neuroscience.2012.10.048.

\title{
Stress and the Developing Adolescent Brain
}

\author{
Lisa Eiland ${ }^{1}$ and Russell D. Romeo ${ }^{2,{ }^{*}}$ \\ ${ }^{1}$ Laboratory of Neuroendocrinology, Rockefeller University, New York, NY 10065 \\ 2Department of Psychology and Neuroscience and Behavior Program, Barnard College of \\ Columbia University, New York, NY 10027
}

\begin{abstract}
Adolescence is a time of continued brain maturation, particularly in limbic and cortical regions, which undoubtedly plays a role in the physiological and emotional changes coincident with adolescence. An emerging line of research has indicated that stressors experienced during this crucial developmental stage may affect the trajectory of this neural maturation and contribute to the increase in psychological morbidities, such as anxiety and depression, often observed during adolescence. In this review, we discuss the short- and long-term effects of periadolescent stress exposure on the structure and function of the brain. More specifically, we examine how stress at prepubertal and early adolescent stages of development affect the morphological plasticity of limbic and cortical brain regions, as well as the enduring effects of adolescent stress exposure on these brain regions in adulthood. We suggest that, due to a number of converging factors during this period of maturation, the adolescent brain may be particularly sensitive to stress-induced neurobehavioral dysfunctions with important consequences on an individual's immediate and long-term health and well-being.
\end{abstract}

\section{INTRODUCTION}

As adolescent individuals transition from childhood to adulthood they reap the benefits of many developmental gains, including increased strength, immune function, and cognitive skills (Dahl, 2004). However, adolescent development can also be a time of significant psychological and physiological vulnerabilities (Andersen, 2003, Dahl, 2004). For instance, disorders such as anxiety, depression, schizophrenia, and drug abuse show marked increases during adolescence (Conger and Petersen, 1984, Spear, 2000, Andersen, 2003, Costello et al., 2003, Dahl, 2004, Patton and Viner, 2007). Though it remains unclear what accounts for these vulnerabilities, exposure to stressors during this stage of development has been proposed to play a significant role (Grant et al., 2003, Grant et al., 2004, Turner and Lloyd, 2004).

Numerous studies have identified a link between exposure to stress and the perturbation of many neurobehavioral processes (McEwen, 2000, 2007). Moreover, these effects of stress appear to be exacerbated when they happen during periods of significant brain maturation, such as the prenatal or neonatal stages of ontogeny (McEwen, 2008, Charil et al., 2010).

\footnotetext{
C 2012 IBRO. Published by Elsevier Ltd. All rights reserved.

"Correspondence to: Russell D. Romeo, Ph.D., Department of Psychology and Neuroscience and Behavior Program, Barnard College of Columbia University, New York, NY 10027, Tel: (212)854-5903, Fax: (212)854-3601, rromeo@ barnard.edu.

Publisher's Disclaimer: This is a PDF file of an unedited manuscript that has been accepted for publication. As a service to our customers we are providing this early version of the manuscript. The manuscript will undergo copyediting, typesetting, and review of the resulting proof before it is published in its final citable form. Please note that during the production process errors may be discovered which could affect the content, and all legal disclaimers that apply to the journal pertain.
} 
Though recent research has drawn attention to the remarkable development exhibited by the adolescent brain (Giedd, 2008, Giedd and Rapoport, 2010), we know relatively little about how stress may affect the brain during this crucial stage of maturation.

In the present review, we examine the nascent body of research on the short- and long-term effects of periadolescent stress exposure on the structure and function of the brain. More specifically, we discuss how stress at prepubertal and early adolescent stages of development affect cortical and limbic brain regions, as well as the enduring effects of adolescent stress exposure on the adult brain. These data suggest that the relative immaturity of the adolescent brain may make it particularly sensitive to stress-induced dysfunctions, with both immediate and lasting consequences on mental health.

\section{DEVELOPMENTAL STAGES}

The studies described in the sections below will focus largely on experiments conducted using basic animal models, namely laboratory rodents. These models have proved invaluable, offering excellent experimental control, while reducing ethical concerns that would be inherent in human studies of stress and brain development. To help put the following animal studies in a developmental context, we provide a brief description of the developmental stages and the approximate age ranges often used with rats and mice.

Prenatal development occurs over a 21 day gestational period. Following parturition, these altricial newborns then experience a protracted period of parental care, lasting 14-21 days. This period of development is often referred to as the neonatal or pre-weanling stage. Weaning from the dam usually happens around 21 days of age after which rodents enter the prepubertal or post-weanling stage. At 30-35 days of age pubertal onset occurs, signaling the beginning of adolescent development.

Although the terms puberty and adolescence are often used interchangeably, and have some chronological overlap, these terms have separate meanings (Sisk and Foster, 2004). In particular, puberty is a distinct stage of development marked by substantial hormonal and somatic changes, often occurring earlier in females than males. Adolescence, however, is a broader term used for the stage of development that begins with the onset of puberty and ends when the attainment of sexual maturity and neurobehavioral characteristics associated with the adult of the species (Sisk and Foster, 2004). The specific age span that covers adolescence in male and female rats and mice is not entirely clear cut, but animals between 30-60 days of age undergo behavioral and neurobiological transformations akin to that observed in other species during adolescence, including humans. For example, it is during this time that social behaviors, such as play, mating, and aggression, as well as alterations in brain gray and white matter volumes, change to their adult-like patterns (Spear, 2000,

Romeo et al., 2002, Gogtay et al., 2004, Juraska and Markham, 2004, Markham et al., 2007, Spear, 2010). Figure 1 provides a schematic of these stages and their approximate age ranges (Figure 1A), along with a simplified time line of human development as a comparison (Figure 1B).

\section{ADOLESCENT MATURATION OF BRAIN AND STRESS REACTIVITY}

The vast majority of research on neural development has centered on prenatal and early neonatal stages of maturation (Sanes et al., 2006). More recently, however, neuroscientists have begun to discover the substantial structural and functional remodeling of the brain, particularly within limbic and cortical regions, that occurs during adolescent development (Giedd et al., 1996a, Giedd et al., 1996b, Giedd et al., 1999, Paus et al., 1999, Sowell et al., 1999, Gogtay et al., 2004). For instance, human and non-human animals studies have shown significant volumetric increases in the hippocampus and amygdala in the early stages of 
puberty (Meyer et al., 1978, Giedd et al., 1996b, Romeo and Sisk, 2001, Andersen and Teicher, 2004, Isgor et al., 2004, Cooke et al., 2007, Payne et al., 2010, Tottenham and Sheridan, 2010). Longitudinal studies combined with structural neuroimaging techniques have also revealed dynamic cortical grey and white matter volume changes throughout adolescence (Giedd et al., 1999, Sowell et al., 1999, Gogtay et al., 2004). Specifically, increases in frontal and temporal cortical volumes are observed from childhood to the onset of puberty, which is then followed by a period of cortical thinning during adolescence and into young adulthood (Giedd et al., 1999, Sowell et al., 1999, Gogtay et al., 2004).

Histological studies in postmortem human and non-human tissue suggest that this phase of cortical thinning, particularly within the frontal cortex, is due in part to synaptic pruning and programmed cell death associated with adolescence (Huttenlocher, 1979, Juraska and Markham, 2004, Markham et al., 2007). Given the involvement of these brain areas in various emotional and cognitive processes, these structural alterations have been posited to moderate the adolescent-related changes in psychological function (Blakemore and Choudhury, 2006, Yurgelun-Todd, 2007, Ernst and Mueller, 2008, Casey et al., 2010, Giedd and Rapoport, 2010, Somerville and Casey, 2010). However, it should be noted that the precise nature of this structure-function relationship in the adolescent brain is unclear (Pfeifer and Allen, 2012).

Along with the continued limbic and cortical maturation, adolescent development is also associated with many shifts in neuroendocrine function (Ojeda and Terasawa, 2002). Relevant to this review is the rather dramatic change in reactivity exhibited by the hypothalamic-pituitary-adrenal (HPA) axis in response to physiological and/or psychological stressors (reviewed in; McCormick and Mathews, 2010, McCormick et al., 2010a, Romeo, 2010a, b). For example, following a variety of acute stressors, prepubertal animals display greater or more protracted hormonal stress responses, as measured by plasma adrenocorticotropin hormone (ACTH) and corticosterone levels, compared to adults (Goldman et al., 1973, Vazquez and Akil, 1993, Romeo et al., 2004a, Romeo et al., 2004b, Romeo et al., 2006b, Foilb et al., 2011, Lui et al., in press); Figure 2A). More specifically, ACTH and corticosterone levels in prepubertal and mid-adolescent animals (30-50 days of age) can take twice as long to return to baseline following a psychological and/or physiological stressor in comparison to their adult (70 days of age) counterparts (Foilb et al., 2011). In addition to these more commonly studied stress-related hormones, experiments have also indicated greater and more protracted stress-induced adrenal progesterone responses prior to adolescent development in both male and female rats (Romeo et al., 2004b, Romeo et al., 2005).

Whether there is a teleological advantage to having heightened hormonal responsiveness during adolescence remains unknown. Given that corticosterone plays a key role in energy mobilization (Sapolsky et al., 2000, Pecoraro et al., 2006) it is possible that enhanced stressinduced corticosterone release during adolescence might allow for greater energy usage to help compensate for the higher basal metabolic demand of adolescence. There is indirect evidence to support this possibility in that adolescent males exposed to $30 \mathrm{~min}$ of restraint stress not only have greater corticosterone release than adults, but also show significantly higher plasma glucose levels (Romeo et al., 2007). Recent evidence, however, implies that in the context of chronic stress the adolescent's ability to mobilize greater energy stores is not sufficient to meet the adolescent's metabolic needs for growth and development. Specifically, three weeks of chronic restraint stress in adults resulted in approximately a $10 \%$ reduction in body weight, whereas the same stress in the adolescent resulted in a $30 \%$ decrease (Eiland et al., 2012). Future work is clearly needed to better understand these differential responses exhibited by the adolescent following stress, and particularly how these responses might be suited to meet the unique physiologic demands of the adolescent. 
It is presently unclear what mediates these age-dependent shifts in HPA reactivity. Notably, the limbic and cortical regions that continue to mature during puberty and adolescence, such as the amygdala, hippocampus, and frontal cortex, are all intimately involved in modulating hormonal stress reactivity in adulthood (Ulrich-Lai and Herman, 2009). However, the exact role these structural changes play in adolescent-related changes in hormonal responsiveness remains unknown. As these regions also display different developmental trajectories, such that amygdala and hippocampus mature earlier than the frontal cortex, it will be important to understand how these areas interact to shape stress reactivity throughout this stage of development.

On a more mechanistic level, a previous study indicated that pre-treatment with the synthetic glucocorticoid, dexamethasone reduced stress-induced corticosterone levels to a greater extent in adults compared to prepubertal rats (Goldman et al., 1973). As these data suggest reduced glucocorticoid-dependent negative feedback in animals prior to puberty, it is possible that prepubertal animal possess fewer receptors that mediate that actions of the glucocorticoids, namely the mineralocorticoid and glucocorticoid receptors (MR and GR, respectively; Ulrich-Lai and Herman, 2009). However, experiments using in situ hybridization to asses MR and GR mRNA levels in the neural-pituitary network that mediates negative feedback on the HPA axis have generally found no age-dependent differences. For instance, hippocampal MR and GR mRNA levels in prepubertal, midpubertal and adult males remain relatively stable (Vazquez, 1998, Romeo et al., 2008), while studies in human and non-human primates (e.g., marmosets) have also shown that GR mRNA levels are steady during the adolescent to adult transition, while MR mRNA levels demonstrate slight decreases (Perlman et al., 2007, Pryce, 2008). We have also recently shown that prepubertal and adult mice also have similar levels of GR protein in hippocampus, medial prefrontal cortex, and hypothalamus before and after adolescent development (Romeo et al., in press). Though it is possible that differences in receptor function exist between the ages, it appears that any pubertal-related change in negative feedback on the HPA axis occurs independently from significant changes in MR and GR levels.

In addition to age, prior stress experience also differentially influences reactivity of the HPA axis. In particular, while adult animals repeatedly exposed to the same stressor show habituated ACTH and corticosterone responses, prepubertal animals exhibit a sensitized response (Romeo et al., 2006a, Doremus-Fitzwater et al., 2009, Lui et al., in press; Figure 2B). Thus, the body of literature derived from studies using basic animal models suggests that if a similar acute or repeated stressor occurs, adolescent animals will experience a greater exposure to stress-related hormones than adults.

To our knowledge, no studies have directly compared hormonal responsiveness in periadolescent and adult humans or investigated possible differences in age- and experiencedependent changes in HPA reactivity. However, there have been reports on changes in boys' and girls' stress reactivity during different stages of adolescence (reviewed in; Dahl and Gunnar, 2009, Spear, 2009, Ordaz and Luna, 2012). In particular, adolescent (13-17 year olds) subjects demonstrated greater performance stress-induced cortisol responses than children (7-12 year olds; Stroud et al., 2009), while another study reported increased cortisol reactivity to Trier Social Stress Test for Children (TSST-C) in 15 year old boys and girls compared to periadolescent individuals at earlier ages (i.e., between 9-13 year olds; Gunnar et al., 2009). It is important to note that in this later study (Gunnar et al., 2009) a few interesting sex differences emerged, such that 13 year old girls showed much greater cortisol reactivity to the TSST-C than 13 year old boys, suggesting that sex plays a significant role in modulating stress reactivity prior to the completion of adolescent maturation. Perhaps future animal studies, which permit hormonal levels to be experimentally manipulated, will help 
parse out the exact contribution of age versus gonadal and/or adrenal maturation on the changes in stress reactivity throughout adolescent development.

The physiological and behavioral implications of these altered hormonal responses during adolescence are currently unknown, but two additional points are worth noting. First, the limbic and cortical regions that continue to mature during adolescence, such as hippocampus, amygdala, and prefrontal cortex, are also some of the most stress reactive areas in the brain (McEwen, 2005). Second, the adolescent brain may be more sensitive to the neuromodulatory roles of stress-related hormones, such as corticosterone. For example, studies have shown that the same dose of corticosterone increased hippocampal NMDA receptor subunit gene expression (e.g., NR2A and NR2B) to a greater degree in prepubertal animals compared to adults (Lee et al., 2003). Thus, from the research reviewed above, it appears a number of neural and hormonal factors converge during adolescent development that could result in heightened sensitivity to stress-induced perturbations of neurobehavioral processes.

\section{STRESS AND THE ADOLESCENT BRAIN}

Although many studies have investigated the effects of stress on the prenatal (Charil et al., 2010), neonatal (McEwen, 2008), adult (McEwen, 2007), and aged brain (Sapolsky, 1999), it is only just recently that we have begun to elucidate the effects of stress on the adolescent brain (Romeo and McEwen, 2006). In fact, it was not until 2004 that the first report investigating the effects of chronic adolescent stress on limbic morphology was published (Isgor et al., 2004). In this study, male rats were exposed to chronic variable stress (CVS) throughout adolescent development (28-56 days of age) and the immediate and long lasting stress-induced volumetric changes of hippocampal subfields were investigated. The hippocampus was examined because of the rich literature on adults that showed how stress causes a reduction in the dendritic complexity of hippocampal pyramidal neurons (McEwen, 1999). The CVS paradigm used consisted of daily exposure to a variety of physical stressors, such as forced swim, restraint, noise, cold, and hypoxia. Twenty-four hours after termination of CVS, CVS-exposed males demonstrated a significant volumetric increase in the pyramidal cell layer of the cornu ammonis 1 (CA1) region of the hippocampus as compared to controls. The CA3 and dentate gyrus (DG) regions were unaffected by CVS at this time point. Interestingly, three weeks after the CVS had been terminated, all three of these hippocampal subfields exhibited significant stress-induced impairment of volumetric growth. In particular, although the controls continued to show substantial hippocampal growth, this expansion was significantly reduced in CA1 and DG regions, and completely arrested in the CA3 layer in CVS-exposed animals (Isgor et al., 2004). It is important to note that these structural changes in the hippocampus coincided with impairment in spatial navigation, as measured by Morris water maze performance (Isgor et al., 2004). Thus, this seminal study provided clear evidence that exposure to stress specifically during the adolescent stage of development could significantly affect both the structure and function of the brain during adolescence and create morbidities that could last well into adulthood.

Another study using the same CVS protocol as above (but administered from 28 to 41 days of age) showed stress-induced changes in the hippocampal mossy fibre system of adolescent male rats (Oztan et al., 2011a). Though the intra/infra pyramidal mossy fibre terminal fields did not show significant stress-induced alterations, the supra-pyramidal mossy fibre terminal fields (SP-MF) did demonstrate stress effects that were dependent upon whether the rat had been previous classified as a novelty low responder (LR) or high responder (HR).

Specifically, there was a significant decrease in the SP-MF volume in CVS-exposed LR rats, but a significant increase in CVS-exposed HRs (Oztan et al., 2011a). Interestingly, in addition to being vulnerable to chronic physical stressors, the adolescent mossy fibre system 
is also vulnerable to chronic social stress. Adolescent HR rats exposed to one of three social stressors (e.g., isolation, novel environment, or crowding) for two hours a day over a two week period demonstrate a significant increase in SP-MF volume (Oztan et al., 2011b). Thus, during adolescence, both physical and social stressors can significantly impact the mossy fibre system. Converging lines of evidence suggest that mossy fibres originating in the DG play a role in the pathophysiology of depression (Kobayashi, 2009). Hence, it is reasonable to posit that stress-induced alterations of mossy fibre connectivity during adolescence might confer increased vulnerability to the development of depressive psychopathologies in individuals with specific responsiveness to novelty.

In addition to the hippocampus, other corticolimbic structures that continue to mature during adolescence, such as the prefrontal cortex and amygdala, also demonstrate significant morphological stress-induced alterations. For instance, in adult male rats, pyramidal neurons in the prefrontal cortex like those in the hippocampus demonstrate stress-induced atrophy (Radley et al., 2004, Liston et al., 2006), whereas pyramidal-like neurons in the basolateral amygdala exhibit stress-induced hypertrophy (Vyas et al., 2002, Vyas et al., 2004). It should be noted, however, that this dendritic remodeling in corticolimbic structures is sex specific, and that females do not always exhibit these stress-induced alterations (Galea et al., 1997, Shansky, 2009).

The impact of stress on structural remodeling of adolescent corticolimbic pyramidal neurons has only recently been examined (Eiland et al., 2012). In this study, chronic restraint stress (CRS) was administered for $6 \mathrm{~h}$ per day during the prepubertal and early adolescent period (days 20 to 41) in both male and female rats. It was found that compared to controls, animals exposed to CRS demonstrated significantly reduced dendritic complexity of pyramidal neurons in the hippocampus and prefrontal cortex, while neurons in the basolateral amygdala displayed increased complexity (Eiland et al., 2012). These CRS-exposed animals also showed elevated depressive-like behaviors (Eiland et al., 2012). Importantly, these effects of stress on dendritic morphology were present in both sexes (Eiland et al., 2012), suggesting that exposure to the pubertal rise in gonadal hormones may organize the sensitivity of the brain to stress in a sex-specific manner.

Just as chronic restraint stress can significantly alter corticolimbic morphology, the social environment of the adolescent has also been reported to affect the structure of the frontal cortex. A recent study showed that when adolescent rats were assigned to a no peer play group (i.e., housing with a single adult) versus single peer or multiple peer play groups (i.e., housing with single or multiple juvenile peers), significant morphological differences were found in the orbitofrontal cortex (OFC) and medial prefrontal cortex (mPFC; Bell et al., 2010). Specifically, it was found that the OFC of animals in the multiple peer play group had significantly more dendritic length and more complex dendritic arbors than the single peer play or no peer play groups. In contrast, in the mPFC, no peer play groups had significantly greater dendritic length and more complex arbors than the single or multiple peer play groups (Bell et al., 2010). Thus, perturbations of the social environment appear to have significant effects on brain structure and function, which may be accentuated during times of development when social interactions are necessary for normal emotional development (Einon and Morgan, 1977). It is also important to note that stressors can profoundly alter social interactions and play behavior in adolescent animals, such that immediately after a brief period of restraint stress social behaviors decrease dramatically in periadolescent rats (Klein et al., 2010). Therefore, any direct effect of physical or psychological stress on brain plasticity may be exacerbated in the adolescent animal because of a reduction in social interactions following the stressor. 
In adults, the effects of stress on hippocampal and prefrontal cortical dendritic morphology are largely reversible, such that if animals are given at least 10 days to recover from the chronic stress, dendritic branching patterns return to pre-stress levels (Conrad et al., 1999, Radley et al., 2005). The stress-induced structural changes in the adult amygdala, however, appear to more enduring with no return to baseline after 3 weeks of recovery (Vyas et al., 2004). Whether or not these effects of adolescent stress on neuronal remodeling noted above are reversible are currently unknown. Notably though, a recent experiment in male rats reported that the synaptic markers spinophilin and synaptophysin were reduced in the prefrontal cortex in young adulthood following social isolation stress from days 30-35 during adolescence (Leussis and Andersen, 2008, Leussis et al., 2008). These changes were reported to persist for 25 days after cessation of the isolation stress (Leussis et al., 2008), suggesting that stress-induced morphological alterations in the adolescent prefrontal cortex may be longer lasting than those observed in adults (Radley et al., 2005).

Though there is a dearth of studies exploring the effects of stress on the adolescent brain, rarer still are studies that directly compare the effects of stress on the adolescent versus adult brain. In other words, do similar stressors have equivalent or different impacts on the brain before and after adolescence? Toth and colleagues (Toth et al., 2008) have recently performed such a study in which they exposed prepubertal (30 days old) and adult (60 days old) male rats to 4 weeks of chronic mild stress (CMS). CMS is a procedure known to produce anhedonic and depressive-like behaviors in adult animals, as indexed by the sucrose preference test (Willner et al., 1992, Willner, 1997). They found that while CMS in adults led to a behavioral phenotype with reduced sucrose preference and mating behavior with a receptive female, young adult males exposed to the CMS procedure during adolescence did not exhibit this anhedonic profile (Toth et al., 2008). Moreover, they found reduced levels of brain-derived neurotrophic factor (BNDF) and neurogenesis in the dentate gyrus of the hippocampal formation of animals exposed to CMS in adulthood, but an increase in these measures in animals exposed to CMS during adolescence (Toth et al., 2008). These data suggest that the same stressors can produce diametrically opposed effects on the brain depending on whether they occurred during adolescence or adulthood.

One caveat to the study above is that only males were assessed, and experiments that have investigated the effects of chronic adolescent stress on sucrose preference in females have found the opposite phenotype, showing a reduction in sucrose preference (Bourke and Neigh, 2011, Eiland et al., 2012). Similarly, experiments have shown that females exposed to chronic restraint stress throughout adolescence (30-52 days of age; Barha et al., 2011) or social instability stress during early- to mid-adolescence (30-45 days of age; McCormick et al., 2010b) exhibit decreases in neurogenesis, and not an increase as reported in males (Toth et al., 2008). Thus, these studies highlight the significant influence that sex has on the effects of adolescent stress on neurobehavioral processes and the importance of factoring sex into these experimental designs.

Taken together, these experiments clearly indicate that the adolescent brain is sensitive to stress, and that the degree of this sensitivity is dependent on type/duration of the stressor, the time at which the stressors are administrated, and the sex of the experimental subject. They also beg more questions, such as how reversible are these effects of stress and what are the mechanisms that may mediate these age-dependent responses. Regardless, this emerging body of research provides strong evidence that stress exposure during adolescence can lead to short- and long-term changes in limbic and cortical structure and function, with important behavioral repercussions. 


\section{OPPORTUNITIES FOR INTERVENTION}

As the studies reviewed above indicate, the continued maturation of the adolescent brain may make it particularly vulnerable to perturbations. However, this developmental plasticity may also make the adolescent brain amenable to interventions to help mitigate earlier emotional and/or physical trauma (Andersen, 2003).

For example, research has begun to examine the ability of environmental enrichment during adolescence to reduce the heightened hormonal stress reactivity and impaired cognitive function in adulthood that results from the neonatal stress of maternal separation (Pryce et al., 2005). Specifically, studies have shown that maternally separated rats exposed to enriched environments (e.g., larger housing, toys, running wheel) during puberty, show reduced stress reactivity and greater cognitive abilities compared to their maternally separated counterparts that were exposed to standard laboratory environments (Francis et al., 2002, Bredy et al., 2003, Bredy et al., 2004). Similar results have also been obtained using enrichment during adolescence to offset negative physiological and behavioral aspects induced by prenatal stress (Morley-Fletcher et al., 2003, Laviola et al., 2004)

Another striking example of adolescent development as a window of opportunity to reduce earlier developmental trauma comes from a study that examined the role of social interactions during puberty to diminish the behavioral deficits caused by a brain lesion (Twiggs et al., 1978). Specifically, in this experiment, prepubertal male rats were housed alone or in groups and then given lesions targeting the medial preoptic nucleus (MPN). The MPN is a hypothalamic nucleus integral for the display of male copulatory behavior (Heimer and Larsson, 1966/1967). Though damage to the MPN in adulthood leads to irreversible deficits in mating behavior (Heimer and Larsson, 1966/1967), males given MPN lesion before puberty were able to show mating behaviors in adulthood, but only if their adolescent development was marked by ample social interactions (Twiggs et al., 1978). Thus, these studies demonstrate the opportunities that exist during adolescence for environmental interventions to diminish, or even reverse, the negative effects of early life adversity.

\section{CONCLUSIONS AND FUTURE DIRECTIONS}

Based on these bourgeoning lines of research, it appears that many factors converge during adolescence that may make this stage of development a particularly sensitive period to stressors, particularly in regards to neurobiological processes. The continued maturation of stress responsive brain regions, the shifts in hormonal reactivity, and the changes in the quantity and quality of stressors that occur at this time may contribute to this heightened sensitivity.

Though some progress has been made in elucidating how stress affects the adolescent brain, many important questions remain unanswered. For instance, what are the cellular, molecular, and genetic mechanisms that mediate these differential sensitivities to stressors as individuals mature? As we begin to understand the effects of stress on epigenetic modifications in the brain (Hunter et al., 2009) and the effects of both context- and germline-dependent epigenetic programming on stress responsiveness (Weaver et al., 2004, Crews et al., 2012), what role may these changes play in long-term and transgenerational effects of stress exposure during adolescence? As different brain regions have different developmental trajectories, are some areas of the brain more or less resilient to stress depending on the stage of adolescent development when one experiences the stress? Because many stress-related psychological disorders demonstrate sex differences (Becker et al., 2007), how do stressors affect adolescent males and females differently? Finally, as has been suggested for early life adversity (Seery, 2011), might stressful experiences within a 
reasonable limit during adolescence insulate the individual from adverse effects of stress later in life? The answers to questions such as these will hopefully shed light on the stressrelated vulnerabilities associated with adolescence as well as inform us about potential interventions to ameliorate disturbances caused by stressors experienced before and/or during adolescence.

\section{Acknowledgments}

Support for work from our laboratories was funded in part by grants from The Undergraduate Science Education Program of the Howard Hughes Medical Institute (R.D.R), Weill Cornell Medical College Friedman Clinical Scholarship in Newborn Medicine (L.E.), National Institute of Mental Health MH-090224 (R.D.R) and MH041245-22S1 (L.E.), and the National Science Foundation IOS-1022148 (to R.D.R.).

\section{References}

Andersen SL. Trajectories of brain development: point of vulnerability or window of opportunity. Neurosci Biobehav Rev. 2003; 27:3-18. [PubMed: 12732219]

Andersen SL, Teicher MH. Delayed effects of early stress on hippocampal development. Neuropsychopharmacology. 2004; 29:1988-1993. [PubMed: 15316569]

Barha CK, Brummelte S, Lieblich SE, Galea LAM. Chronic restraint stress in adolescence differentially influences hypothalamic-pituitary-adrenal axis function and adult hippocampal neurogenesis in male and female rats. Hippocampus. 2011; 21:1216-1227. [PubMed: 20665592]

Becker JB, Monteggia LM, Perrot-Sinal TS, Romeo RD, Taylor JR, Yehuda R, Bale TL. Stress and disease: is being female a predisposing factor? J Neurosci. 2007; 27:11851-11855. [PubMed: 17978023]

Bell HC, Pellis SM, Kolb B. Juvenile peer play experience and the development of the orbitofrontal and medial prefrontal cortex. Behav Brain Res. 2010; 207:7-13. [PubMed: 19786051]

Blakemore S-J, Choudhury S. Development of the adolescent brain: implications for executive function and social cognition. J Child Psychol Psychiatr. 2006; 47:296-312.

Bourke CH, Neigh GN. Behavioral effects of chronic adolescent stress are sustained and sexually dimorphic. Horm Behav. 2011; 60:112-120. [PubMed: 21466807]

Bredy TW, Humpartzoomian RA, Cain DP, Meaney MJ. Partial reversal of the effect of maternal care on cognitive function through environmental enrichment. Neuroscience. 2003; 118:571-576. [PubMed: 12699791]

Bredy TW, Zhang TY, Grant RJ, Diorio J, Meaney MJ. Peripubertal environmental enrichment reverses the effects of maternal care on hippocampal development and glutamate receptor subunit expression. Eur J Neurosci. 2004; 20:1355-1362. [PubMed: 15341607]

Casey BJ, Duhoux S, Cohen MM. Adolescence: what do transmission, transition, and translation have to do with it? Neuron. 2010; 67:749-760. [PubMed: 20826307]

Charil A, Laplante DP, Vaillancourt C, King S. Prenatal stress and brain development. Brain Res Rev. 2010; 65:56-79. [PubMed: 20550950]

Conger, J.; Petersen, A. Adolescence and youth: psychological development in a changing world. New York: Harper and Row; 1984.

Conrad CD, Magarinos AM, LeDoux JE, McEwen BS. Repeated restraint stress facilitates fear conditioning independently of causing hippocampal CA3 dendritic atrophy. Behav Neurosci. 1999; 113:902-913. [PubMed: 10571474]

Cooke BM, Jordan CL, Breedlove SM. Pubertal growth of the medial amygdala delayed by short photoperoids in the Siberian hamster, Phodopus sungorus. Horm Behav. 2007; 52:283-288. [PubMed: 17604030]

Costello EJ, Mustillo S, Erkanli A, Keeler G, Angold A. Prevalence and development of psychiatric disorders in childhood and adolescence. Arch Gen Psychiatr. 2003; 60:837-844. [PubMed: 12912767] 
Crews D, Gillette R, Scarpino SV, Manikkam M, Savenkova MI, Skinner MK. Epigenetic transgenerational inheritance of altered stress response. Proc Natl Acad Sci USA. 2012; 109:91439148. [PubMed: 22615374]

Dahl RE. Adolescent brain development: a period of vulnerabilities and opportunities. Ann NY Acad Sci. 2004; 1021:1-22. [PubMed: 15251869]

Dahl RE, Gunnar MR. Heightened stress responsiveness and emotional reactivity during pubertal maturation: implications for psychopathology. Dev Psychopathol. 2009; 21:1-6. [PubMed: 19144219]

Doremus-Fitzwater TL, Varlinskaya EI, Spear LP. Social and non-social anxiety in adolescent and adult rats after repeated restraint. Physiol Behav. 2009; 97:484-494. [PubMed: 19345235]

Eiland L, Ramroop J, Hill MN, Manely J, McEwen BS. Chronic juvenile stress produces corticolimbic dendritic architectural remodeling and modulates emotional behavior in male and female rats. Psychoneuroendocrinology. 2012; 37:39-47. [PubMed: 21658845]

Einon DF, Morgan MJ. A critical period for social isolation in the rat. Dev Psychobiol. 1977; 10:123132. [PubMed: 838157]

Ernst M, Mueller SC. The adolescent brain: insights from functional neuroimaging research. Dev Neurobiol. 2008; 68:729-743. [PubMed: 18383544]

Foilb AR, Lui P, Romeo RD. The transformation of hormonal stress responses throughout puberty and adolescence. J Endocrinol. 2011; 210:391-398. [PubMed: 21746793]

Francis DD, Diorio J, Plotsky PM, Meaney MJ. Environmental enrichment reverses the effects of maternal separation on stress reactivity. J Neurosci. 2002; 22:7840-7843. [PubMed: 12223535]

Galea LAM, McEwen BS, Tanapat P, Deak T, Spencer RL, Dhabhar FS. Sex differences in dendritic atrophy of CA3 pyramidal neurons in response to chronic restraint stress. Neuroscience. 1997; 81:689-697. [PubMed: 9316021]

Giedd JN. The teen brain: insights from neuroimaging. J Adolesc Health. 2008; 42:335-343. [PubMed: 18346658]

Giedd JN, Blumenthal J, Jeffries NO, Castellanos FX, Liu H, Zijdenbos A, Paus T, Evans AC, Rapoport JL. Brain development during childhood and adolescence: a longitudinal MRI study. Nature Neurosci. 1999; 2:861-863. [PubMed: 10491603]

Giedd JN, Rapoport JL. Structural MRI of pediatric brain development: what have we learned and where are we going? Neuron. 2010; 67:728-734. [PubMed: 20826305]

Giedd JN, Snell JW, Lange N, Rajapakse JC, Casey BJ, Kozuch PL, Vaituzis AC, Vauss YC, Hamburger SD, Kaysen D, Rapoport JL. Quantitative magnetic resonance imaging of human brain develpoment: ages 4-18. Cerebral Cortex. 1996a; 6:551-560. [PubMed: 8670681]

Giedd JN, Vaituzis AC, Hamburger SD, Lange N, Rajapakse JC, Kaysen D, Vauss YC, Rapoport JL. Quantitative MRI of the temporal lobe, amygdala, and hippocampus in normal human development: ages 4-18 years. J Comp Neurol. 1996b; 366:223-230. [PubMed: 8698883]

Gogtay N, Giedd JN, Lusk L, Hayashi KM, Greenstein D, Vaituzis AC, Nugent TF, Herman DH, Clasen LS, Toga AW, Rappoport JL, Thompson PM. Dynamic mapping of human cortical development during childhood through early adulthood. Pro Natl Acad Sci USA. 2004; 101:81748179.

Goldman L, Winget C, Hollingshead GW, Levine S. Postweaning development of negative feedback in the pituitary-adrenal system of the rat. Neuroendocrinology. 1973; 12:199-211. [PubMed: 4353346]

Grant KE, Compas BE, Stuchlmacher AF, Thurn AE, McMahon SD, Halpert JA. Stressors and child and adolescent psychopathology: moving from markers to mechanisms of risk. Psychol Bull. 2003; 129:447-466. [PubMed: 12784938]

Grant KE, Compas BE, Thurm AE, McMahon SD, Gipson PY. Stressors and child and adolescent psychopathology: measurement issues and prospective effects. J Clin Child Adolesc Psychol. 2004; 33:412-425. [PubMed: 15136206]

Gunnar MR, Wewerka S, Frenn K, Long JD, Griggs C. Developmental changes in hypothalamuspituitary-adrenal activity over the transition to adolescence: normative changes and associations with puberty. Dev Psychopathol. 2009; 21:69-85. [PubMed: 19144223] 
Heimer L, Larsson K. /1967) Impairment of mating behavior on male rats following lesions of the preoptic-anterior hypothalamic continuum. Brain Res. 1966; 3:248-263.

Hunter RG, McCarthy KJ, Milne TA, Pfaff DW, McEwen BS. Regulation of hippocampal H3 histone methylation by acute and chronic stress. Proc Natl Acad Sci USA. 2009; 106:20912-20917. [PubMed: 19934035]

Huttenlocher PR. Synaptic density in human frontal cortex- developmental changes and effects of aging. Brain Res. 1979; 163:195-205. [PubMed: 427544]

Isgor C, Kabbaj M, Akil H, Watson SJ. Delayed effects of chronic variable stress during peripubertaljuvenile period on hippocampal morphology and on cognitive and stress axis functions in rats. Hippocampus. 2004; 14:636-648. [PubMed: 15301440]

Juraska JM, Markham JA. The cellular basis for volume changes in the rat cortex during puberty: white and gray matter. Ann NY Acad Sci. 2004; 1021:431-435. [PubMed: 15251923]

Klein ZA, Padow VA, Romeo RD. The effects of stress on play and home cage behaviors in adolescent male rats. Dev Psychobiol. 2010; 52:62-70. [PubMed: 19937741]

Kobayashi K. Targeting the hippocampal mossy fibre synapse for the treatment of psychiartic disorders. Mol Neurobiol. 2009; 39:24-36. [PubMed: 19130314]

Laviola G, Rea M, Morley-Fletcher S, Di Carlo S, Bacosi A, De Simone R, Bertini M, Pacifici R. Beneficial effects of enriched environment on adolescent rats from stressed pregnancies. Eur $\mathbf{J}$ Neurosci. 2004; 20:1655-1664. [PubMed: 15355333]

Lee PR, Brandy D, Koenig JI. Corticosterone alters N-methyl-D-aspartate receptor subunit mRNA expression before puberty. Mol Brain Res. 2003; 115:55-62. [PubMed: 12824055]

Leussis MP, Andersen SL. Is adolescence a sensitive period for depression? behavioral and neuroanatomical findings form a social stress model. Synapse. 2008; 62:22-30. [PubMed: 17957735]

Leussis MP, Lawson K, Stone K, Andersen SL. The enduring effects of an adolescent social stressor on synaptic density, part II: poststress reversal of synaptic loss in the cortex by adinazolam and MK-801. Synapse. 2008; 62:185-192. [PubMed: 18081181]

Liston C, Miller MM, Goldwater DS, Radley JJ, Rocher AB, Hof PR, Morrison JH, McEwen BS. Stress-induced alterations in frontal cortical dendritic morphology predict selective impairments in perceptual attentional set-shifting. J Neurosci. 2006; 26:7870-7874. [PubMed: 16870732]

Lui P, Padow VA, Franco D, Hall BS, Park B, Klein ZA, Romeo RD. Divergent stress-induced neuroendocrine and behavioral responses prior to puberty. Physiol Behav. (in press).

Markham JA, Morris JR, Juraska JM. Neuron number decreases in the rat ventral, but not dorsal, medial prefrontal cortex between adolescence and adulthood. Neuroscience. 2007; 144:961-968. [PubMed: 17137726]

McCormick CM, Mathews IZ. Adolescent development, hypothalamic-pituitary-adrenal function, and programming of adult learning and memory. Prog Neuro-Psychopharmacol Biol Psychiatr. 2010; 34:756-765.

McCormick CM, Mathews IZ, Thomas C, Waters P. Investigations of HPA function and the enduring consequences of stressors in adolescence in animal models. Brain Cogn. 2010a; 72:73-85. [PubMed: 19616355]

McCormick CM, Nixon F, Thomas C, Lowie B, Dyck J. Hippocampal cell proliferation and spatial memory performance after social instability stress in adolescence in female rats. Behav Brain Res. 2010b; 208:23-29. [PubMed: 19900485]

McEwen BS. Stress and hippocampal synaptic plasticity. Ann Rev Neurosci. 1999; 22:105-122. [PubMed: 10202533]

McEwen BS. The neurobiology of stress: from serendipity to clinical relevance. Brain Res. 2000; 886:172-189. [PubMed: 11119695]

McEwen BS. Glucocorticoids, depression, and mood disorders: structural remodeling in the brain. Metabol Clin Exp. 2005; 54:20-23.

McEwen BS. Physiology and neurobiology of stress and adaptation: central role of the brain. Physiol Rev. 2007; 87:873-904. [PubMed: 17615391]

McEwen BS. Understanding the potency of stressful early life experiences on brain and body function. Metabol Clin Exp. 2008; 57:S11-S15. 
Meyer G, Ferres-Torres R, Mas M. The effects of puberty and castration on hippocampal dendritic spines of mice. A Golgi study. Brain Res. 1978; 155:108-112. [PubMed: 688003]

Morley-Fletcher S, Rea M, Maccari S, Laviola G. Environmental enrichment during adolescence reverses the effects of prenatal stress on play behaviour and HPA axis reactivity in rats. Eur J Neurosci. 2003; 18:3367-3374. [PubMed: 14686910]

Ojeda, SR.; Terasawa, E. Neuroendocrine regulation of puberty. In: Pfaff, DW., et al., editors. Hormones, Brain and Behavior. Vol. 4. New York: Elsevier; 2002. p. 589-659.

Ordaz S, Luna B. Sex differences in physiological reactivity to acute psychopsocial stress in adoelscence. Psychoneuroendocrinology. 2012; 37:1135-1157. [PubMed: 22281210]

Oztan O, Aydin C, Isgor C. Chronic variable physical stress during the peripubertal-juvenile period causes differential depressive and anxiogenic effects in the novelty-seeking phenotype: fucntional implications for hippocampal and amygdalar brain-derived neurotrophic factor and the mossy fibre plasticity. Neuroscience. 2011a; 192:334-344. [PubMed: 21767611]

Oztan O, Aydin C, Isgor C. Stressful environmental and social stimulation in adolescence causes antidepressant-like effects associated with epigentic induction of the hippocampal BDNF and mossy fibre sprouting in the novelty-seeking phenotype. Neurosci Lett. 2011b; 501:107-111. [PubMed: 21767606]

Patton GC, Viner R. Pubertal transitions in health. Lancet. 2007; 369:1130-1139. [PubMed: 17398312]

Paus T, Zijdenbos A, Worsley K, Collins DL, Blumenthal J, Giedd JN, Rapoport JL, Evans AC. Structural maturation of neural pathways in children and adolescents: in vivo study. Science. 1999; 283:1908-1911. [PubMed: 10082463]

Payne C, Machado CJ, Bliwise NG, Bachevalier J. Maturation of the hippocampal formation and amygdala in Macaca mulatta: a volumetric magnetic resonance imaging study. Hippocampus. 2010; 20:922-935. [PubMed: 19739247]

Pecoraro N, Dallman MF, Warne JP, Ginsberg AB, Laugero KD, la Fleur SE, Houshyar H, Gomez F, Bhargava A, Akana SF. From Malthus to motive: how the HPA axis engineers the phenotype, yoking needs to wants. Prog Neurobiol. 2006; 79:247-340. [PubMed: 16982128]

Perlman WR, Webster MJ, Herman MM, Kleinman JE, Weickert CS. Age-related differences in glucocorticoid receptor mRNA levels in the human brain. Neurobiol Aging. 2007; 28:447-458. [PubMed: 16540204]

Pfeifer JH, Allen NB. Arrested development? reconsidering dual-systems models of brain function in adolescence and disorders. Trend Cogn Sci. 2012; 16:322-329.

Pryce CR. Postnatal ontogeny of expression of the corticosteroid receptor genes in mammalian brains: inter-species and intra-species differences. Brain Res Rev. 2008; 57:596-605. [PubMed: 17916381]

Pryce CR, Ruedi-Bettschen D, Dettling AC, Weston A, Russig H, Ferger B, Feldon J. Long-term effects of early-life environmental manipulations in rodents and primates: potential animal models in depression research. Neurosci Biobehav Rev. 2005; 29:649-674. [PubMed: 15925698]

Radley JJ, Rocher AB, Janssen WGM, Hof PR, McEwen BS, Morrison JH. Reversibility of apical dendritic retraction in the rat medial prefrontal cortex following repeated stress. Exp Neurol. 2005; 196:199-203. [PubMed: 16095592]

Radley JJ, Sisti HM, Hao J, Rocher AB, McCall T, Hof PR, McEwen BS, Morrison JH. Chronic behavioral stress induces apical dendritic reorganization of pyramidal neurons of the medial prefrontal cortex. Neuroscience. 2004; 125:1-6. [PubMed: 15051139]

Romeo RD. Adolescence: a central event in shaping stress reactivity. Dev Psychobiol. 2010a; 52:244253. [PubMed: 20175102]

Romeo RD. Pubertal maturation and programming of hypothalamic-pituitary-adrenal reactivity. Front Neuroendocrinol. 2010b; 31:232-240. [PubMed: 20193707]

Romeo RD, Ali FS, Karatsoreos IN, Bellani R, Chhua N, Vernov M, McEwen BS. Glucocorticoid receptor mRNA expression in the hippocampal formation of male rats before and after pubertal development in response to acute and repeated stress. Neuroendocrinology. 2008; 87:160-167. [PubMed: 17923777] 
Romeo RD, Bellani R, Karatsoreos IN, Chhua N, Vernov M, Conrad CD, McEwen BS. Stress history and pubertal development interact to shape hypothalamic pituitary adrenal axis plasticity. Endocrinology. 2006a; 147:1664-1674. [PubMed: 16410296]

Romeo RD, Bellani R, McEwen BS. Stress-induced progesterone secretion and progesterone receptor immunoreactivity in the paraventricular nucleus are modulated by pubertal development in male rats. Stress. 2005; 8:265-271. [PubMed: 16423715]

Romeo RD, Kaplowitz ET, Ho A, Franco D. The influence of puberty on stress reactivity and forebrain glucocorticoid receptor levels in inbred and outbred strains of male and female mice. Psychoneuroendocrinology. (in press).

Romeo RD, Karatsoreos IN, Ali FS, McEwen BS. The effects of acute stress and pubertal development on metabolic hormones in the rat. Stress. 2007; 10:101-106. [PubMed: 17454971]

Romeo RD, Karatsoreos IN, McEwen BS. Pubertal maturation and time of day differentially affect behavioral and neuroendocrine responses following an acute stressor. Horm Behav. 2006b; 50:463-468. [PubMed: 16836997]

Romeo RD, Lee SJ, Chhua N, McPherson CR, McEwen BS. Testosterone cannot activate an adult-like stress response in prepubertal male rats. Neuroendocrinology. 2004a; 79:125-132. [PubMed: 15103225]

Romeo RD, Lee SJ, McEwen BS. Differential stress reactivity in intact and ovariectomized prepubertal and adult female rats. Neuroendocrinology. 2004b; 80:387-393. [PubMed: 15741744]

Romeo RD, McEwen BS. Stress and the adolescent brain. Ann NY Acad Sci. 2006; 1094:202-214. [PubMed: 17347352]

Romeo RD, Richardson HN, Sisk CL. Puberty and the maturation of the male brain and sexual behavior: recasting a behavioral potential. Neurosci Biobehav Rev. 2002; 26:379-389.

Romeo RD, Sisk CL. Pubertal and seasonal plasticity in the amygdala. Brain Res. 2001; 889:71-77. [PubMed: 11166688]

Sanes, DH.; Reh, TA.; Harris, WA. Development of the Nervous System. Burlington, MA: Elsevier Academic Press; 2006.

Sapolsky RM. Glucocorticoids, stress, and their adverse neurological effects: relevance to aging. Exp Gerontol. 1999; 34:721-732. [PubMed: 10579633]

Sapolsky RM, Romero LM, Munck AU. How do glucocorticoids influence stress responses? Integrating permissive, suppressive, stimulatory, and preparative actions. Endocr Rev. 2000; 21:55-89. [PubMed: 10696570]

Seery MD. Resilience: a silver lining to experiencing adverse life events? Curr Dir Psychol Sci. 2011; 20:390-394.

Shansky RM. Estrogen, stress and the brain: progress toward unraveling gender discrepancies in major depressive disorders. Expert Rev Neurother. 2009; 9:967-973. [PubMed: 19589047]

Sisk CL, Foster DL. The neural basis of puberty and adolescence. Nature Neurosci. 2004; 7:10401047. [PubMed: 15452575]

Somerville LH, Casey BJ. Developmental neurobiology of cognitive control and motivational systems. Curr Opin Neurobiol. 2010; 20:236-241. [PubMed: 20167473]

Sowell ER, Thompson PM, Colin JH, Jernigan TL, Toga AW. In vivo evidence for post-adolescent brain maturation in frontal and striatal regions. Nature Neurosci. 1999; 2:859-861. [PubMed: 10491602]

Spear LP. The adolescent brain and age-related behavioral manifestations. Neurosci Biobehav Rev. 2000; 24:417-463. [PubMed: 10817843]

Spear LP. Heightened stress responsivity and emotional reactivity during pubertal maturation: implications for psychopathology. Dev Psychopathol. 2009; 21:87-97. [PubMed: 19144224]

Spear, LP. The Behavioral Neuroscience of Adolescence. New York: Norton; 2010.

Stroud LR, Foster E, Papandonatos GD, Handwerger K, Granger DA, Kivlighan KT, Niaura R. Stress response and the adolescent transition: performance versus peer rejection stressors. Dev Psychopathol. 2009; 21:47-68. [PubMed: 19144222] 
Toth E, Gersner R, Wilf-Yarkoni A, Raizel H, Dar DE, Richter-Levin G, Levit O, Zangen A. Agedependent effects of chronic stress on brain plasticity and depressive behavior. J Neurochem. 2008; 107:522-532. [PubMed: 18752645]

Tottenham N, Sheridan MA. A review of adversity, the amygdala and the hippocampus: a consideration of developmental timing. Front Human Neurosci. 2010; 3:1-18.

Turner RJ, Lloyd DA. Stress burden and the lifetime incidence of psychiatric disorder in young adults. Arch Gen Psychiatr. 2004; 61:481-488. [PubMed: 15123493]

Twiggs DG, Popolow HB, Gerall AA. Medial preoptic lesions and male sexual behavior: age and environmental interactions. Science. 1978; 200:1414-1415. [PubMed: 663624]

Ulrich-Lai YM, Herman JP. Neural regulation of endocrine and autonomic stress responses. Nature Rev Neurosci. 2009; 10:397-409. [PubMed: 19469025]

Vazquez DM. Stress and the developing limbic-hypothalamic-pituitary-adrenal axis. Psychoneuroendocrinology. 1998; 23:663-700. [PubMed: 9854741]

Vazquez DM, Akil H. Pituitary-adrenal response to ether vapor in the weanling animal: characterization of the inhibitory effect of glucocorticoids on adrenocorticotropin secretion. Pediatr Res. 1993; 34:646-653. [PubMed: 8284104]

Vyas A, Mitra R, Rao BSS, Chattarji S. Chronic stress induces contrasting patterns of dendritic remodeling in hippocampus and amygdala neurons. J Neurosci. 2002; 22:6810-6818. [PubMed: 12151561]

Vyas A, Pillai AG, Chattarji S. Recovery after chronic stress fails to reverse amygdaloid neuronal hypertrophy and enhanced anxiety-like behavior. Neuroscience. 2004; 128:667-673. [PubMed: 15464275]

Weaver ICG, Cervoni N, Champagne FA, D’Alessio AC, Sharma S, Seckl JR, Dymov S, Szyf M, Meaney MJ. Epigenetic programming by maternal behavior. Nature Neurosci. 2004; 7:847-854. [PubMed: 15220929]

Willner P. The chronic mild stress procedure as an animal model of depression: valid, reasonably reliable, and useful. Psychopharmacol. 1997; 134:371-377.

Willner P, Muscat R, Papp M. Chronic mild stress-induced anhedonia: a realistic animal model of depression. Neurosci Biobehav Rev. 1992; 16:525-534. [PubMed: 1480349]

Yurgelun-Todd D. Emotional and cognitive changes during adolescence. Curr Opin Neurobiol. 2007; 17:251-257. [PubMed: 17383865] 
Adolescent development is marked by continued maturation of the brain. Adolescence in also a time of substantial shifts in stress reactivity.

The interaction of stress and adolescent brain development is discussed.

This interaction may mediate the adolescent-related increased in psychopathologies. 
A. Rodent (e.g., rat, mouse)

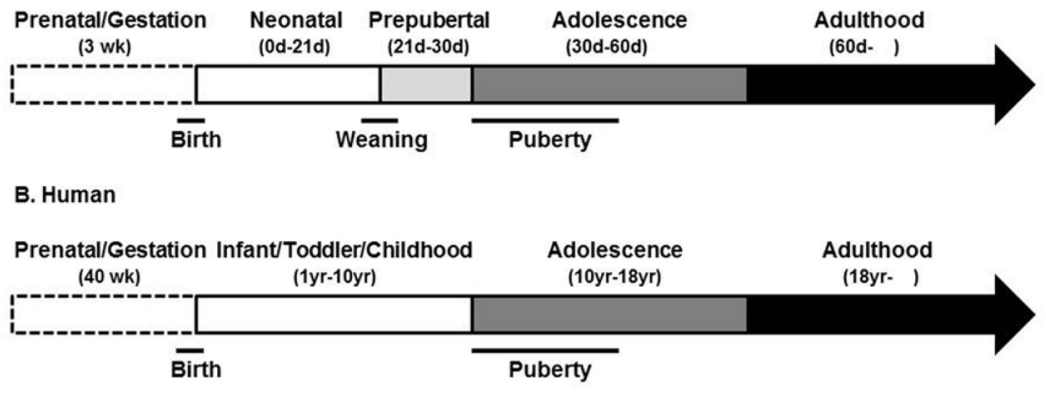

Figure 1.

Time lines of development in rodents (e.g., rats and mice, A) and humans (B) along with approximate age ranges and commonly used terms for referring to those stages of development. Abbreviations: d, day; wk, week; yr, year. 


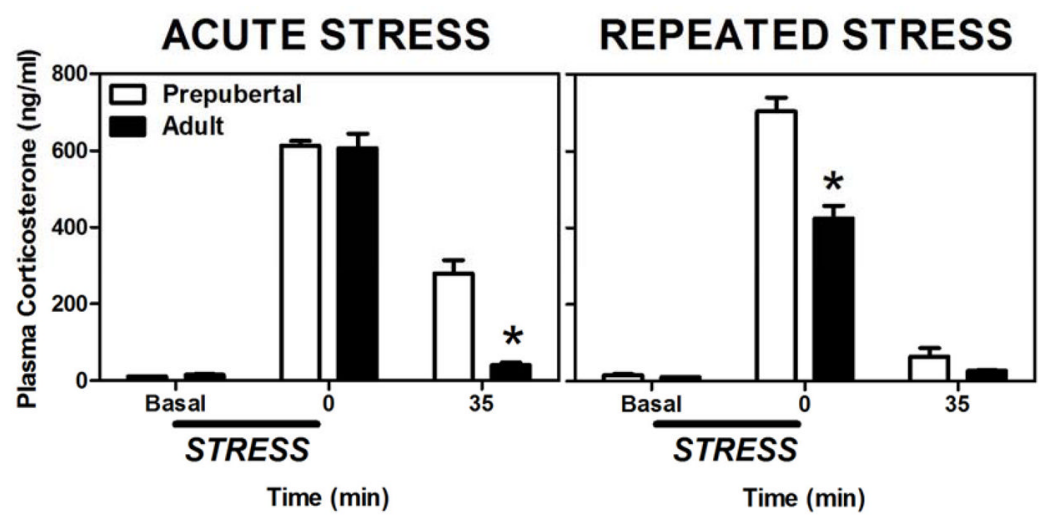

Figure 2.

Mean ( \pm SEM) plasma corticosterone in prepubertal (30 days old) and adult (70 days old) male rats before, during, or after a single 30 min session of restraint stress (left panel) or 30 min sessions of restraint administered daily for eight days (right panel). Asterisks indicate a significant difference between prepubertal and adult animals at that time point. Adapted from (Lui et al., in press). 
A. Hippocampus CA3 Region

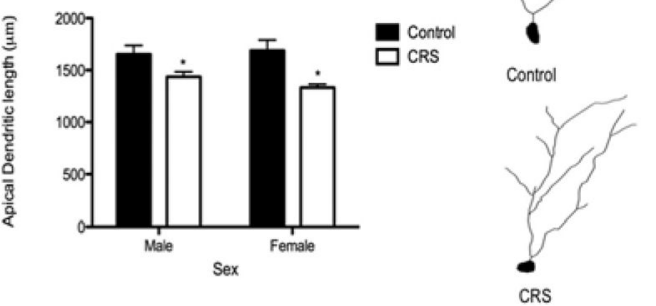

B. Medial Prefrontal Cortex Prelimbic Region
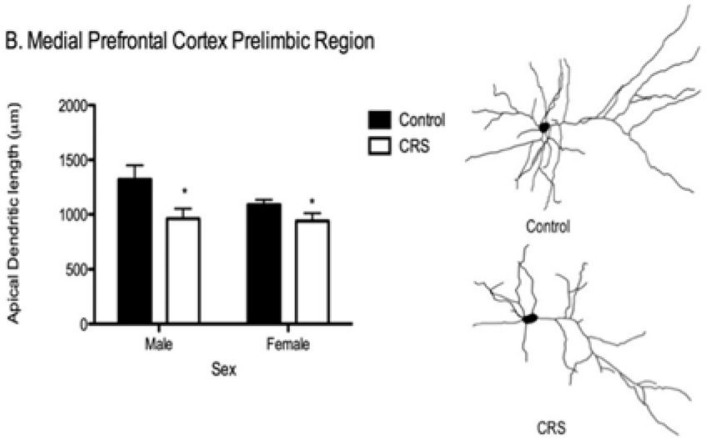

C. Basolateral Amygdala
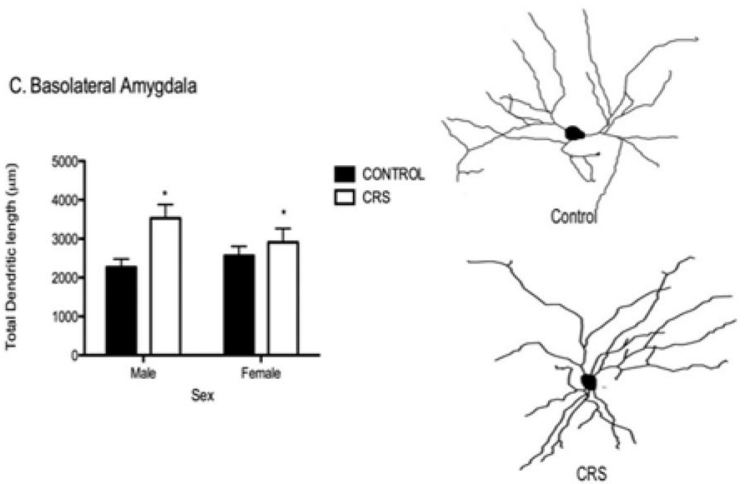

Figure 3.

Representative tracings and data plots for the effects of chronic restraint stress (CRS) during adolescence on apical dendritic remodeling in both males and females in the CA3 region of the hippocampus (A), the medial prefrontal cortex prelimbic region (B), and basolateral amygdala (C). Asterisks indicate a significant difference between CRS and control animals. Note dendritic atrophy in the hippocampus and prefrontal cortex, but dendritic hypertrophy in the amygdala. Adapted from (Eiland et al., 2012). 